
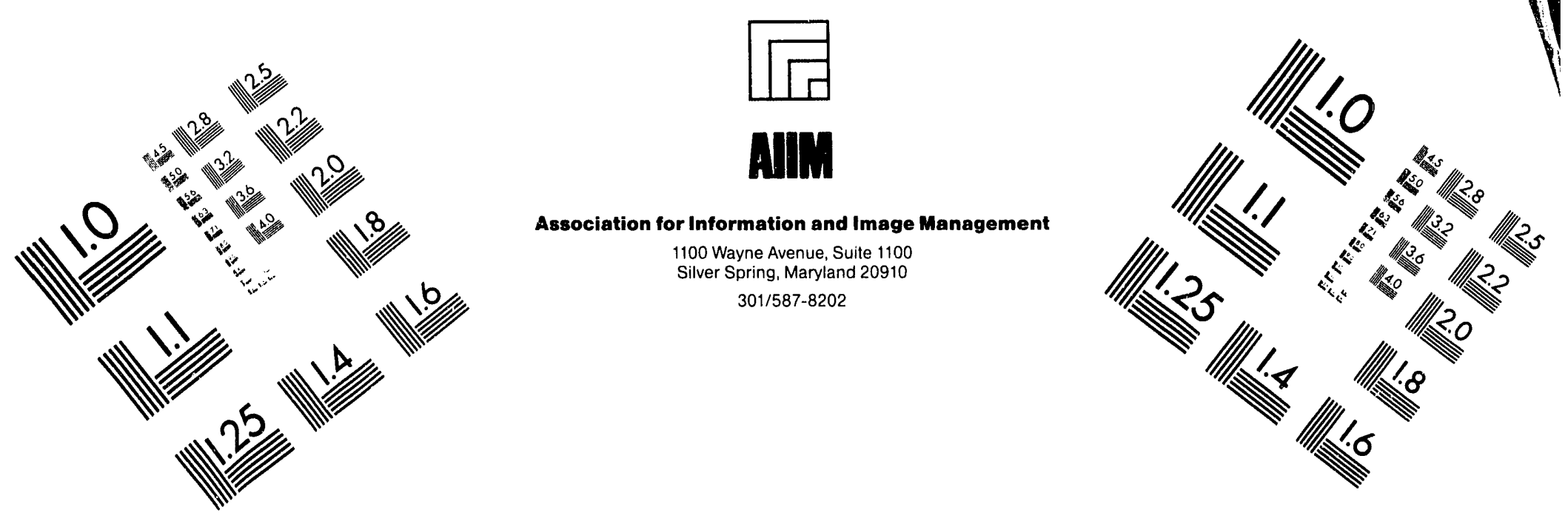

\title{
Centimeter
}

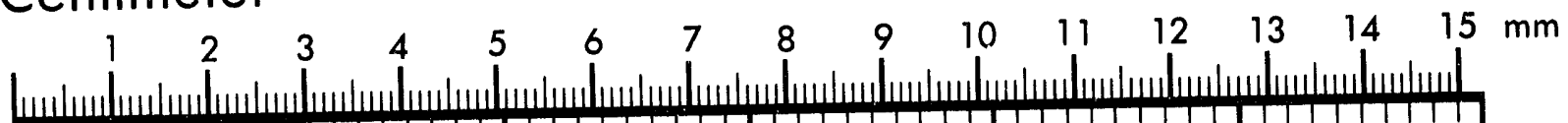

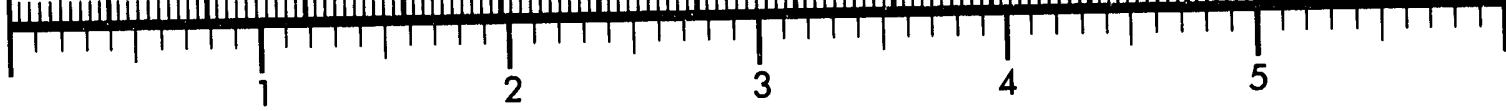
Inches
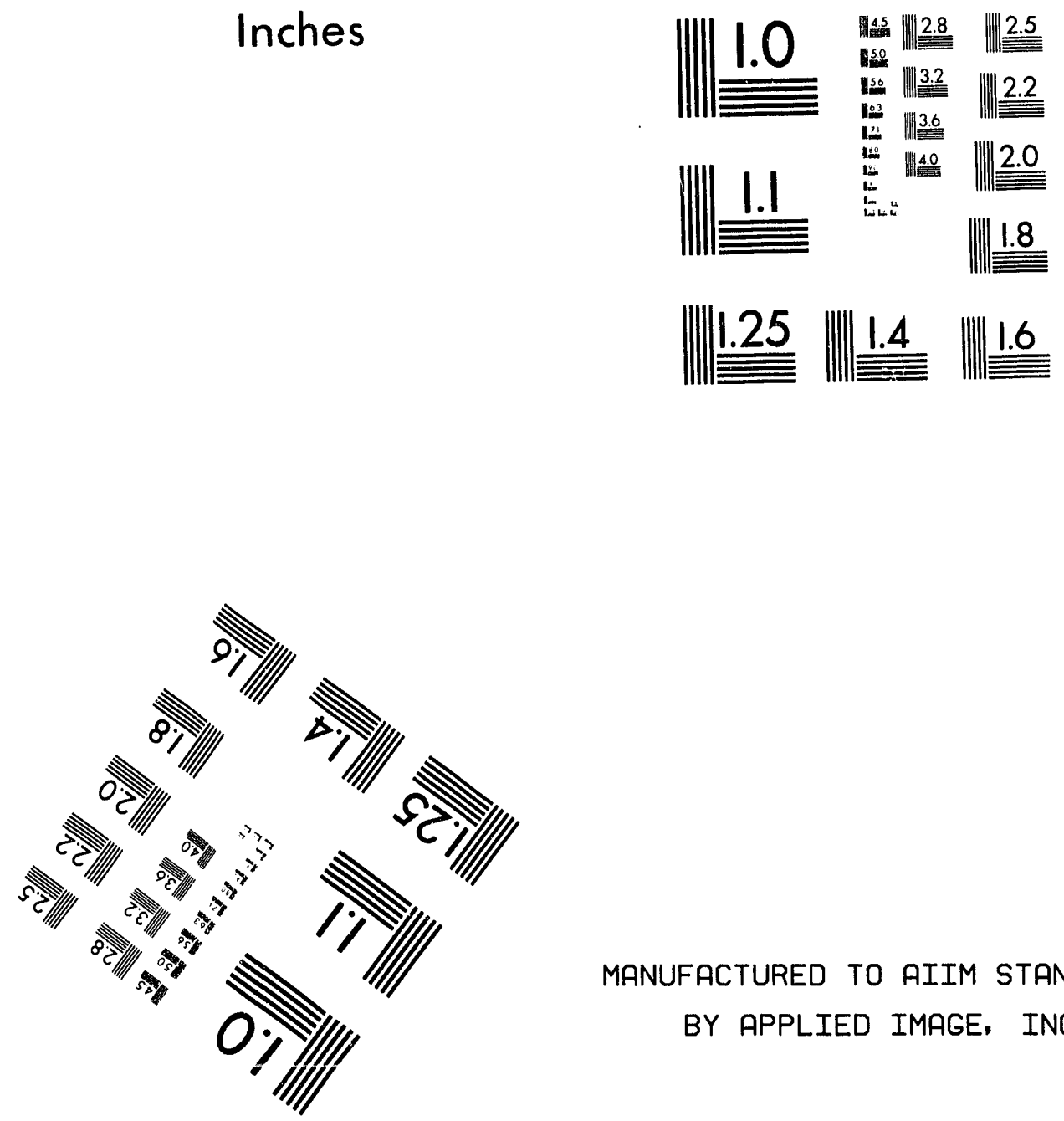

MANUFACTURED TO AIIM STANDARDS

BY APPLIED IMAGE, INC.

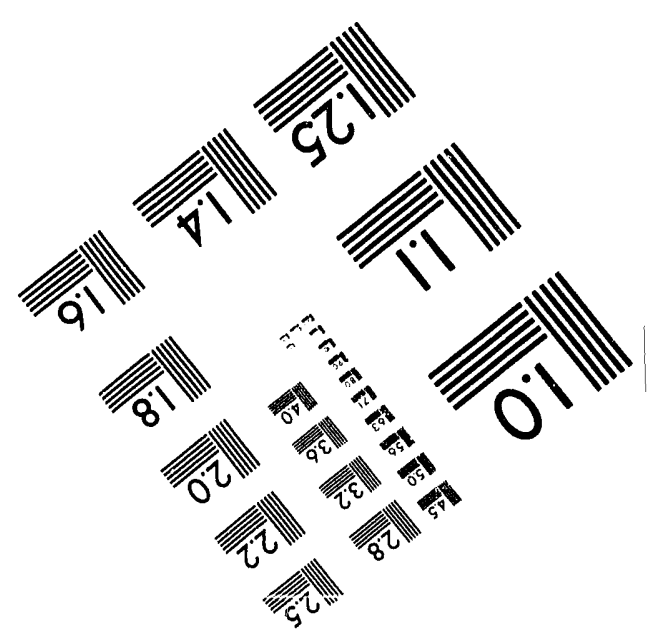



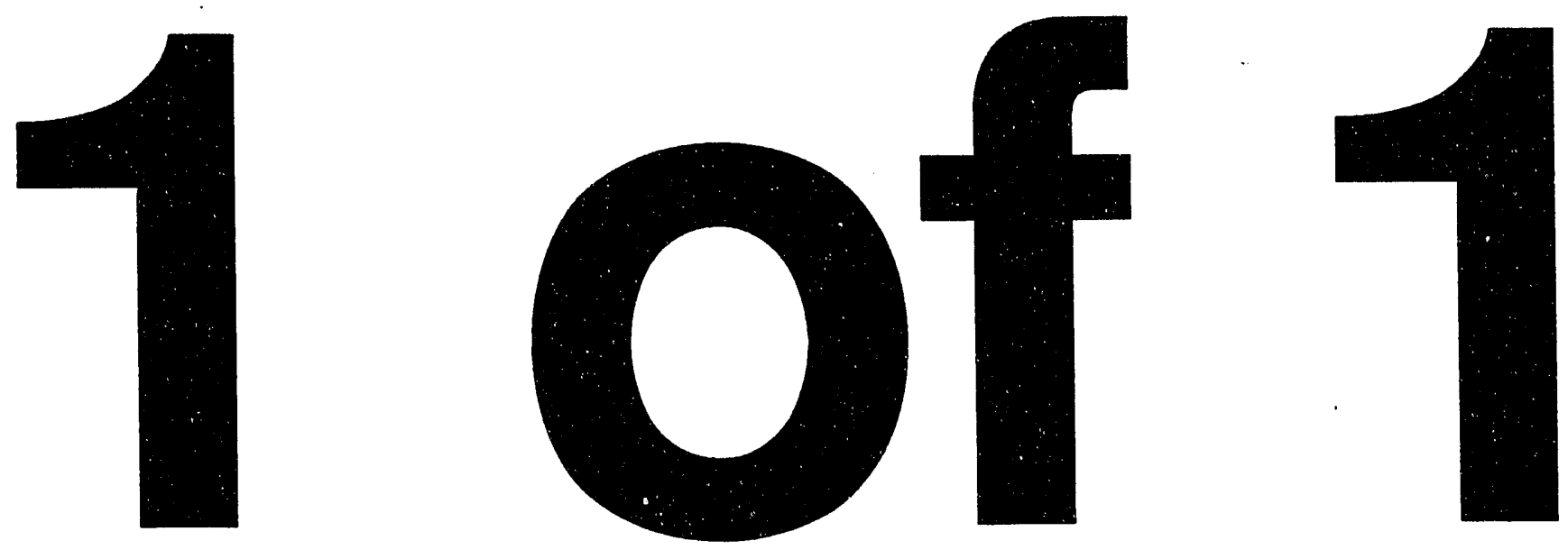


\title{
Con $9303193-1$
}

UCRL-JC- 112831

PREPRINT

\section{SUPERHARDNESS EFFECT}

IN Au/Ni MULTILAYERS

\author{
A. F. Jankowski
}

This paper was prepared for submittal to

The First International Symposium on Metallic Multilayers

in Kyoto, Japan on March 1-5, 1993.

March 1993

This is a preprint of a paper intended for publication in a joumal or proceedings. Since changes may be made before publication, this preprint is made available with the understanding that it will not be cited or reproduced without the permission of the author.

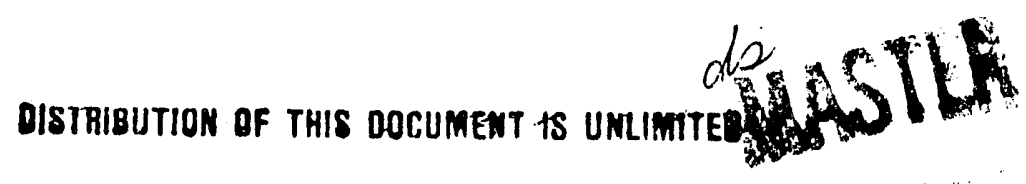




\section{DISCLAIMER}

This document was prepared as an account of work sponsored by an agency of the United States Government. Neither the United States Government nor the University of California nor any of their employees, makes any warranty, express or implied, or assumes any legal liability or responsibility for the accaracy, completeness, or meffatness of any information, apparatus, product, or process disclosed, or represents that its use would not infringe privately owned rights. Reference herein to any specific commercial produ is, process, or service by trade name, trademark, manufacturer, or otherwise, does not necessarily constitute or imply its endorsement, recommendation, or favoring by the United States Government or the University of California. The views and opinions of authors expressed herein do not necessarily state or reflect those of the United States Government or the University of Californie, and shall not be ased for advertising or product endorsement parposes. 


\title{
Superhardness Effect in Au/Ni Multilayers
}

\author{
Alan F. Jankowski \\ Lawrence Livermore National Laboratory, Department of Chemistry \& Materials Science \\ University of California, Livermore, California 94550
}

\begin{abstract}
The presence of an enhanced hardness, that is a 'Superhardness Effect', is found as a behavior parallel to the Supermodulus Effect in $\mathrm{Au} / \mathrm{Ni}$ multilayer structures. The submicron thick $\mathrm{Au} / \mathrm{Ni}$ coatings are prepared by magnetron sputter deposition. A microindenier is used to measure load as a function of indentation depth. An increase in hardness is measured as the Au/Ni layer pair spacing decreases. A local maximum in hardness occurs for samples with layer pairs consisting of 4-6 atomic planes of each metal component.
\end{abstract}

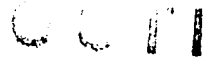




\section{INTRODUCTION}

The Supermodulus Effect is a several-fold increase, beyond a rule-of-mixtures value, in the elastic constants of a metallic multilayer system. The increase in the in-plane elastic moduli, as measured using a variety of mechanical tests ${ }^{[1-4]}$ and acoustic wave methods ${ }^{[5]}$, are found over a narrow range(s) of composition wavelengths. The structure of a metallic multilayer is remarkably sensitive to the synthesis conditions of the deposition process. Differences that are produced on an atomic scale (as in lattice coherency and composition amplitude) to differences on a microscopic scale (as in grain size, orientation and growth morphology) influence the magnitude of the change in the mechanical behavior. The Supermodulus Effect is known to be linked with the presence of coherently strained layers. This investigation is focused on the microhardness variations of a noble/transition metal system which exhibits the supermodulus effect, specifically $\mathrm{Au} / \mathrm{Ni}$ multilayers.

An increase of hardness is observed in layered thin films as the layer pair spacing $\lambda$ decreases. The presence of each layer interface is an obstacle to the passage of dislocations. Thus, the increase in hardness is a result of an increase in the number of interfaces per unit volume. The increase in hardness is found to be inversely proportional to $\lambda 0.5$ for simply layered structures. This well-known Hall-Petch relationship is confirmed for both small and large increases of hardness in layered systems. For $0.1 \mu \mathrm{m} \mathrm{Cu} / \mathrm{Ni}$ layer pairs the hardness is increased to $300 \%$ the rule-of-mixtures value and for $0.2 \mu \mathrm{m} \mathrm{Cu} / \mathrm{Fe}$ layer pairs the hardness is increased to $200 \%$ the rule-of-mixtures value. ${ }^{[6]}$ For $\mathrm{Cu} / \mathrm{Cr}$ laminates, only a $10 \%$ increase is found beyond the rule-ofmixtures value. ${ }^{[7]}$

The additional presence of lattice coherency, as seen in metallic multilayers with nanometer scaled layer pairs, is found to introduce a local maximum in hardness. The maxima in hardness occurs for layer pairs consisting of 4-6 atomic planes of each metal constituent, wherein the coherency strains have their maximum magnitude. In $\mathrm{Au} / \mathrm{Ni}$ multilayers, both the in-plane and 
normal strain components are maximum for layer pair spacings of $\sim 2 \mathrm{~nm} .{ }^{[8-9]}$ Microindentation measurements for TiN/VN superlattices oriented along [100] show a maximum hardness which is $275 \%$ the rule-of-mixtures value for $\lambda=5.2 \mathrm{~nm}$ (i.e. 6 atomic planes of both TiN and VN per layer). ${ }^{[10]}$ An increase in the Vickers microhardness is similarly measured for TiN/NbN [100] superlattices with a local maximum of a $270 \%$ increase for $\lambda=4.6 \mathrm{~nm}$. ${ }^{[11]}$

For submicron thick films probed with nanometer scaled indentations, a variation in the hardness measured for a single film will occur with different indentation depths.[12] At some critical depth, the influence of the substrate on the measured film hardness will become pronounced. For the case of films which are soft in comparison to hard substrates, the measured hardness will increase beyond the critical indentation depth. A method of analysis needs to be established in order to determine the hardness of a thin film on a substrate. A technique for determining the critical indentation depth is based on the well-known Meyer relation between the applied load $L$ and the indentation diagonal $d .{ }^{[13]}$ For bulk materials, a plot of $\log L$ vs $\log d$, generally produces a straight line. For thin film coatings, a deviation from the straight line occurs at the indentation depth where the substrate begins to influence the indentation process. ${ }^{[14]}$ Hardness values determined below the critical indentation depth $D_{C}$ are representative of the coating alone whereas values determined above the critical indentation depth represent the film-substrate composite. For multilayer structures, wherein the hardness may vary as a function of layer pair spacing, the critical indentation depth $D_{c}$ should be ideally determined from Meyer Plots for each sample uniquely. In the analysis presented, Meyer Plots will be constructed using load as a function of the indentation depth $D$, since the indentation depth is directly proportional to the indentation diagonal. 


\section{EXPERIMENTS}

\section{A. Sample Preparation}

The Au/Ni multilayer samples are prepared by planar magnetron sputtering in the $\mathrm{dc}$ mode. ${ }^{[9,15]}$ The deposition is based on the sequential rotation of $\mathrm{Si}(100)$ substrates positioned 20 $\mathrm{cm}$ above a circular array of individually shielded, sputtering sources. The oxygen-free copper substrate table is maintained near room temperature $\left(<40^{\circ} \mathrm{C}\right)$ during the deposition. The target materials are 0.99995 pure $\mathrm{Ni}$ and 0.997 pure $\mathrm{Au}$. A $6.7 \times 10^{-1} \mathrm{~Pa}$ working argon gas pressure is used to sputter the target materials whereas the cryogenically pumped system base pressure is $6.7 \times 10^{-6} \mathrm{~Pa}$. A constant deposition flux, between 0.1 and $1.0 \mathrm{~nm} \mathrm{~s}^{-1}$, is maintained for each multilayer coating. Multilayers with layer pair spacings $\lambda$ between 0.82 and $9.0 \mathrm{~nm}$ (listed in Table I) are prepared in this way where $N$ is the number of layer pairs and $t$ is the film thickness. The nominal composition of each sample, based on calibrated $6 \mathrm{MHz}$ quartz crystal thickness monitors, is $\mathrm{Au}_{0.5} \mathrm{Ni}$ 0.5. Coatings of $\mathrm{Au}$ and $\mathrm{Ni}, 0.2 \mu \mathrm{m}$ thick, are prepared for comparison to the $\mathrm{Au} / \mathrm{Ni}$ multilayer samples.

\section{B. X-Ray Diffraction}

The Au/Ni multilayers are characterized with $\mathrm{Cu} K \alpha \mathrm{x}$-ray diffraction (XRD). ${ }^{[8,16]} \mathrm{A}$ powder diffractometer equipped with a graphite monochromator is operated in the $\theta / 2 \theta$ mode. The $\mathrm{x}$-ray diffraction data characteristically show a (111) Bragg reflection with high and low angle satellite reflections (as seen in Fig. 1). The separation measured between the satellite reflections and the $\mathrm{Au} / \mathrm{Ni}(111)$ Bragg reflection yields an average layer pair spacing for the $9 \mathrm{~nm}$ sample. For reference, the (111) interplanar spacings of pure $\mathrm{Au}$ and $\mathrm{Ni}$ are 0.236 and $0.203 \mathrm{~nm}$, respectively. The full width at half maximum is less than $0.75^{\circ}$ for the diffraction peaks of all $\mathrm{Au} / \mathrm{Ni}$ samples. These Au/Ni multilayers are uniquely textured along the [111] growth direction. The intensities of the satellite reflections about (111) are used to calculate the shape of the composition profile. A 
Guinier analysis has been developed to calculaie the composition profile from the $\theta / 2 \theta$ scans. [17] The analysis yields a square wave approximation of a sinusoidal composition variation for each $\mathrm{Au} / \mathrm{Ni}$ sample. A dynamical theory of $\mathrm{x}$-ray diffraction is used to fit the $\theta / 2 \theta$ scans with a strain profile in the composition modulation direction. ${ }^{[8]}$

\section{Transmission Electron Microscopy}

The $\mathrm{Au} / \mathrm{Ni}$ multilayers are characterized by transmission electron microscopy (TEM) of samples imaged in cross-section. Details of the sample preparation technique for cross-section imaging are presented elsewhere[15]. Bright field images of samples viewed in cross-section typically show a dense, columnar growth structure with subgrain diameters of 30-60 nm (as seen in Fig. 2). The individual gold (appearing dark) and nickel (light) layers are discrete and continuous across the column boundaries. These $\mathrm{Au} / \mathrm{Ni}$ multilayers, deposited at room temperature, have a flat surface. (Note that the rms surface roughness as measured using a Nomarski type scanning instrument is found to be less than $0.3 \mathrm{~nm}$ for all $\mathrm{Au} / \mathrm{Ni}$ samples.) Selected-area, electron diffraction patterns (SADPs) of the cross-sectioned samples reveal a single to multiple phase transition as the layer pair spacing $\lambda$ increases ${ }^{[15]}$. The reflections of twinned $\mathrm{Au}(111)$ and $\mathrm{Ni}(111)$ layers are present in the 9nm layer pair SADP (see Fig. 2 insert).

D. Microindentation

Microindentation techniques have been developed to measure hardness from thin films on substrates. The hardness of a film can be determined from indentation load - displacement data. [18] A NanoIndenter is used to obtain the indentation load - displacement data. Indentation arrays for each sample consist of six indentations at each of six maximum depths. The load is varied from sample to sample in order to achieve the same maximum depths. The indenter is initially loaded at a velocity of $3-6 \mathrm{~nm} \mathrm{~s}^{-1}$, then held at the peak load until the velocity decreases below $0.1 \mathrm{~nm} \mathrm{~s}^{-1}$, 
and finally unloaded at a constant rate. Loads and indentation depths are measureable above 0.25 $\mu \mathrm{N}$ and to within $0.3 \mathrm{~nm}$, respectively. The hardness is equivalent to the peak indentation load divided by the projected contact area of the indenter impression. The contact area is proportional to the square of the indentation depth. The indentation depth is determined by extrapolating the initial $25 \%$ of the indentation unloading curve, using a least squares fit of a straight line, to zero load. The method of determining contact area through an effective indentation depth is more accurate than using either the indentation depth at peak load or the final depth. Limitations to the assumptions of linear unloading and the flat punch approximation for the indenter tip can affect the current results by uniformly decreasing the measured hardness values by $10-15 \%$. 19$]$

\section{MICROHARDNESS RESULTS}

The Meyer Plot for the Ni(111) coating, modified to present load as function of indentation depth, clearly shows the transition from indenting only the film to measuring the hardness contribution of the $\mathrm{Si}(100)$ substrate (in Fig. 3). Even for indents as shallow as 30nm, the tangent to the load vs depth curve for increasing load shows that the effects of the substrate are just beginning to diminish. The hardness vs indentation depth curves which correspond to the $\mathrm{Au}$ and $\mathrm{Ni}$ coatings again show the transition of measuring the substrate effect to just the coating hardness as the indentation depth decreases below $4 \mathrm{~nm}$ (in Fig. 4). The Ni hardness curve shows the transition from the coating (at 7.0 GPa) below a $3-4 \mathrm{~nm}$ depth to the substrate (at $13.9 \mathrm{GPa}$ ) above a $150 \mathrm{~nm}$ depth. The Au film smears under plastic deformation which masks the full effect of the Si substrate until the depth exceeds the full coating thickness. The Au hardness is measured (at 1.3 $\mathrm{GPa}$ ) below a $4 \mathrm{~nm}$ indentation. The continuous change in hardness above indentation depths of 4 $\mathrm{nm}$ reflecting the increasing magnitude of the substrate effect show the necessity to use the shallowest indentation depths in order to measure only the coating hardness. 
The load vs indentation depth curve of the $9 \mathrm{~nm} \mathrm{Au} / \mathrm{Ni}$ multilayer (in Fig. 5) shows the critical indentation depth to be $3 \mathrm{~nm}$. Deviation of the load curve away from the film tangent shows the influence of the substrate as the indentation depth increases. The load vs depth curve is fitted to the average load of six data sets at each indentation depth. A plot of the corresponding hardness values for each $9 \mathrm{~nm} \mathrm{Au} / \mathrm{Ni}$ load-indentation depth data set (in Fig. 6) again shows the substrate effect. The hardness continuously increases above an indentation depth of $4 \mathrm{~nm}$ for the $9 \mathrm{~nm} \mathrm{Au} / \mathrm{Ni}$ sample. The hardness of the coating alone just becomes evident below indentation depths of $4 \mathrm{~nm}$.

The hardness vs indentation depth curves for all the Au/Ni multilayer samples (in Fig. 6) show the substrate-film average at indentation depths $>100 \mathrm{~nm}$. The softer coatings (as the $0.82 \mathrm{~nm}$ sample) produce a lower average than the harder coatings (as the $1.77 \mathrm{~nm}$ sample). Below the $100 \mathrm{~nm}$ depth, the hardness continuously changes until the film hardness is measured alone. The critical indentation depth $D_{c}$ changes for each sample since each film with a different layer pair spacing $\lambda$ has a unique hardness. Even for the shallowest indentation depth, the effect of the substrate is just becoming minimal. A plot of the hardness variation with layer pair spacing $\lambda$ is shown for each set of indentation depths (in Fig. 7). The maximum variation in hardness is observed at the shallowest indentation depth ( $3 \mathrm{~nm})$. The rule-of-mixtures value for $\mathrm{Au}_{0.5}-\mathrm{Ni}_{0.5}$ is plotted (as determined from Fig. 3) for comparison to the multilayer results.

The need to use the smallest indentation depth is clear to minimize the substrate effect on measured film hardness. The layer flatness observed in the TEM cross-section micrographs ${ }^{[9,15]}$ (as Fig. 2) eliminates any concern of surface roughness affecting the hardness variation for decreasing indentation depths. The peak hardness is measured for the $\sim 2 \mathrm{~nm}$ Au/Ni layer pair spacing. The peak hardness is twice the rule-of-mixtures average (a $100 \%$ increase). The $9 \mathrm{~nm}$ sample increases by only $30 \%$, the least amount for any sample. 


\section{DISCUSSION}

The hardness values determined for the Au and Ni films, as well as $\mathrm{Si}$, are comparable with results from other microindenation experiments. A nearly identical value is reported for Au (1.0 $\mathrm{GPa})$ using the same indentation instrument $[20]$, whereas reported values for $\mathrm{Ni}(4.2 \mathrm{GPa})$ and $\mathrm{Si}$ $(9.1 \mathrm{GPa})$ measured using a $5 \mathrm{gf}$ load in a Vickers indenter ${ }^{[14]}$ are in correct proportion. The ASTM recommendation ${ }^{[21]}$ to measure the coating hardness at a indentation depth/film thickness $D / t<0.1$ is clearly evidenced in this study. Although the critical depth will vary from one $\mathrm{Au} / \mathrm{Ni}$ layer pair spacing to the next, the affects of the substrate on the hardness measurement are just diminished at $D / t<0.06-0.08$.

The hardness peak at a layer pair spacing $\lambda$ of $\sim 2 \mathrm{~nm}$ is consistent with both the supermodulus peak and magnetic anisotropy energy peak for the Au/Ni system (in Fig. 8). The biaxial modulus is calculated from the spacings of in-plane diffraction peaks. ${ }^{[9]}$ The total anisotropy energy represents the difference in energy density measured between the parallel and perpendicular states. ${ }^{[22]}$ (The easy magnetization direction is in-plane.) The origin of all these enhanced physical properties are linked to the underlying microstructure. The superlattice distortions in $\mathrm{Au} / \mathrm{Ni}$ multilayers have been extensively characterized using XRD and TEM.[8-9] The dynamical theory of $\mathrm{x}$-ray diffraction is utilized to obtain calculated diffraction curves for each $\mathrm{Au} / \mathrm{Ni}$ sample by an iterative fitting to the amplitude and angular spacings of the measured (111) Bragg reflection(s) and corresponding satellite peaks. This procedure indicates that the $\mathrm{Au}$ and $\mathrm{Ni}$ layers are strained along the [111] growth direction. The interface spacings of $\mathrm{Au}$ and $\mathrm{Ni}$ are equivalent, but relax to unstrained values away from the interfaces. The laiger layer pair spacings $(\lambda>2-3 \mathrm{~nm})$ have complete relaxation away from the interface into the layer, whereas the shorter layer pairs $(\lambda<2-3 \mathrm{~nm})$ do not have complete relaxation. The computed interplanar spacings indicate the nickel layers to be in tension whereas the gold layers are in compression along the modulation direction. 
For $\mathrm{Au} / \mathrm{Ni}$ layer pair spacings $\lambda>2 \mathrm{~nm}$, the (111) reflections of the SADP(s) correspond to strained planar spacings. Coincident with the [112] pole projection of the cross-section, diffraction patterns are the (220) reflections. The (220) reflection corresponds to the 'in-plane' spacing which is perpendicular to the (111) spacing of the modulation direction. The (220) is singular for $\lambda<2 \mathrm{~nm}$ indicating in-plane coherency between the Au and Ni layers. The presence of (220) reflections from $\mathrm{Au}$ and $\mathrm{Ni}$ are additionally present for $\lambda>2 \mathrm{~nm}$. The measured average spacing for the (220) Au and $\mathrm{Ni}$ approach unstrained values as the layer pair increases to $4.4 \mathrm{~nm}$, wherein the intermediate spacing corresponding to the interface vanishes.

Intensity traces of digitized high resolution electron microscopy images of samples viewed in cross-section are used to simultaneously generate (111) and (220) Au/Ni spacings. A periodic planar spacing variation along the modulation [111] is revealed through the $\mathrm{Au}$ and Ni layers as found by both $\mathrm{x}$-ray diffraction and SADP electron microscopy analysis. Unstrained spacings (111), as measured in the bulk state of nickel and gold, are found away from the Au-Ni interfaces. The average (111) spacings for the Au and Ni layers, in addition to the intermediate spacing of the interface, converge as $\lambda$ decreases. The average (220) spacings for $\mathrm{Au}$ and $\mathrm{Ni}$ likewise converge as $\lambda$ decreases. Both the Au and Ni layers are coherent (in-plane) at $\lambda \sim 2 \mathrm{~nm}$ where the (220) lattice misfit is zero.

The individual layers of $\mathrm{Au}$ and $\mathrm{Ni}$ do not follow a direct Poisson effect, that is contraction perpendicular to the direction of expansion. The individual layers of Ni expand both in-plane and along the modualtion direction, although not necessarily to the same magnitude. The expansion of the Ni lattice may originate to structurally match the Au lattice during the growth process. The mutual solid solubility of $\mathrm{Au}$ and $\mathrm{Ni}$ does suggest the feasibility of an epitaxial and lattice matched (coherent) growth process. Whereas the local layer distortions do not follow a normal Poisson effect, the averaged planar spacings for the integrated multilayer structure should if the resultant structure behaves as a continuum body. The average Au-Ni planar spacings at each layer pair 
spacing $\lambda$ do follow the Poisson relation. The net in-plane compression accompanied by out-ofplane expansion has been suggested for metallic superlattice systems [23].

\section{SUMMARY}

The hardness of $\mathrm{Au} / \mathrm{Ni}(111)$ multilayers, deposited on $\mathrm{Si}(100)$ substrates by magnetron sputtering, is measured using microindentation. The hardness of the coatings is found to be dependent on the layer pair spacing of the multilayer. The indentation depth critically affects the influence of the substrate on the measurement of the coating hardness. Indentation depths below $15-8 \%$ of the $\mathrm{Au} / \mathrm{Ni}$ film thickness are needed to isolate the film contribution. A peak hardness enhancement of $100 \%$ is found for $\lambda \sim 2 \mathrm{~nm}$. The maximum hardness increase of $100 \%$ diminishes above and below $\lambda \sim 2 \mathrm{~nm}$ to a minimum incresae of $30 \%$. The dependency of hardness on $\lambda$ is a behavior that parallels the enhancement of the biaxial modulus found in noble/transition metal multilayer systems. The terminology of a Supermodulus Effect' can be extended to the measurement of microhardness as a 'Superhardness Effect'.

\section{Acknowledgments}

Thanks are given to M.A. Wall of LLNL for providing the electron microscopy image. Appreciation is also expressed to Prof. W.D. Nix and S.P. Baker of Stanford University for the cooperation in obtaining microindentation measurements of these $\mathrm{Au} / \mathrm{Ni}$ multilayer samples. This work was performed under the auspices of the United States Department of Energy by Lawrence Livermore National Laboratory under contract \#W-7405-Eng-48. 


\section{REFERENCES}

1. W.M.C. Yang, T. Tsakalakos and J.E. Hilliard, J. Appl. Phys. 48 (1977) 876.

2. A. Jankowski and T. Tsakalakos, J. Appl. Phys. 57 (1985) 1835.

3. L.R. Testardi, R.H. Willens, J.T. Krause, D.B. McWhan and S. Nakahara, J. Appl. Phys. 52 (1981) 510.

4. A. Fartash, I.K. Schuller and M. Grimsditch, Appl. Phys. Lett. 55 (1989) 2614; Phys. Rev. B (in press).

5. J.R. Dutcher, S. Lee, J. Kim, J.A. Bell, G.I. Stegeman and C.M. Falco, Mater. Sci. Eng'g. B 6 (1990) 199.

6. R.F. Bunshah, R. Nimmagadda, H.J. Doerr, B.A. Movchan, N.I. Grechanuk and E.V. Badizha, Thin Solid Films 72 (1980) 261.

7. R.F. Bunshah, R. Nimmagadda, H.J. Doerr, B.A. Movchan, N.I. Grechanuk and G.G. Didkin, Thin Solid Films 112 (1984) 227.

8. J. Chaudhuri, V. Gondhalekar and A.F. Jankowski, J. Appl. Phys. 71 (1992) 3816.

9. A.F. Jankowski, J. Appl. Phys. 71 (1992) 1782.

10. U. Helmersson, S. Todorova, S.A Barnett, J.E. Sundgren, L.C. Markert and J.E. Greene, J. Appl. Phys. 62 (1987) 481.

11. M. Shinn, L. Hultman and S.A. Barnett, J. Mater. Res. 7 (1992) 901.

12. B.D. Fabes, W.C. Oliver, R.A. McKee and F.J. Walker, J. Mater. Res. 7 (1992) 3056.

13. G.F. Van der Voort, Metallography Principles and Practice (McGraw-Hill, New York, 1984).

14. C. Feldman, F. Ordway and J. Bernstein, J. Vac. Sci. Technol. A 8 (1990) 117.

15. M.A. Wall and A.F. Jankowski, Thin Solid Films 181 (1989) 313.

16. A.F. Jankowski, Superlattices and Microstructures 6 (1989) 427.

17. G.E. Henein and J.E. Hilliard, J. Appl. Phys. 54 (1983) 728. 
18. M.F. Doerner and W.D. Nix, J. Mater. Res. 1 (1986) 601.

19. W.C. Oliver and G.M. Pharr. J. Mater. Res. 7 (1992) 1564.

20. T.P. Weihs, S. Hong, J.C. Bravman and W.D. Nix, J. Mater. Res. 3 (1988) 931.

21. ASTM Standard E 92, Annual Book of Standards 3.01 (American Society for Testing and Materials, Philadelphia, 1987) 264.

22. J.R. Childress, C.L. Chien and A.F. Jankowski, Phys. Rev. B 45 (1992) 2855.

23. A.F. Jankowski, Mater. Sci. Eng'g. A 114 (1989) L17. 
Table 1. Au/Ni Multilayer Sample Dimensions

$\begin{array}{lrrrrrr}\lambda(\mathrm{nm}) & 0.82 & 1.24 & 1.77 & 2.51 & 4.41 & 9.00 \\ N & 570 & 380 & 193 & 190 & 100 & 25 \\ t(\mathrm{~nm}) & 470 & 495 & 390 & 505 & 485 & 230\end{array}$




\section{Figure Captions}

1. A CuK $\alpha$ x-ray diffraction scan of a $9 \mathrm{~nm} \mathrm{Au} / \mathrm{Ni}$ multilayer using a powder diffractometer equipped with a graphite monochromator operated in the $\theta / 2 \theta$ mode. The order of each satellite reflection is indicated above (+) and below (-) the $\mathrm{Au} / \mathrm{Ni}(111) \mathrm{Bragg}$ reflection (0).

2. A transmission electron microscopy bright field image and selected area diffraction pattern of a 25 layer pair $9 \mathrm{~nm} \mathrm{Au} / \mathrm{Ni}$ multilayer sample viewed in cross-section reveals a dense, columnar growth structure with a flat surface and both discrete and continuous layering across columnar boundaries. The growth direction is indicated with an arrow.

3. A microindentation load vs indentation depth plot of a $0.2 \mu \mathrm{m}$ thick Ni coated $\mathrm{Si}(100)$ substrate.

4. The hardness vs indentation depth plots of $\mathrm{Au}(111)$ and Ni(111) coated Si substrates show the transition from measuring the hardness of the coating to sensing the effect of the substrate as indentation depth increases.

5. A microindentation load vs indentation depth plot of a $9 \mathrm{~nm} \mathrm{Au} / \mathrm{Ni}$ multilayer coated $\mathrm{Si}(100)$ substrate.

6. The hardness vs indentation depth plots of $\mathrm{Au} / \mathrm{Ni}(111)$ multilayer coated Si substrates show the transition from measuring the hardness of the coating to sensing the effect of the substrate as indentation depth increases.

7. A local maximum is measured for the hardness vs layer pair spacing plots of $\mathrm{Au} / \mathrm{Ni}(111)$ multilayer coated Si substrates.

8. A local maximum is measured for the magnetic anisotropy energy ${ }^{[22]}$ and calculated for the biaxial modulus ${ }^{[9]}$ variation with layer pair spacing of $\mathrm{Au} / \mathrm{Ni}$ multilayer samples. 


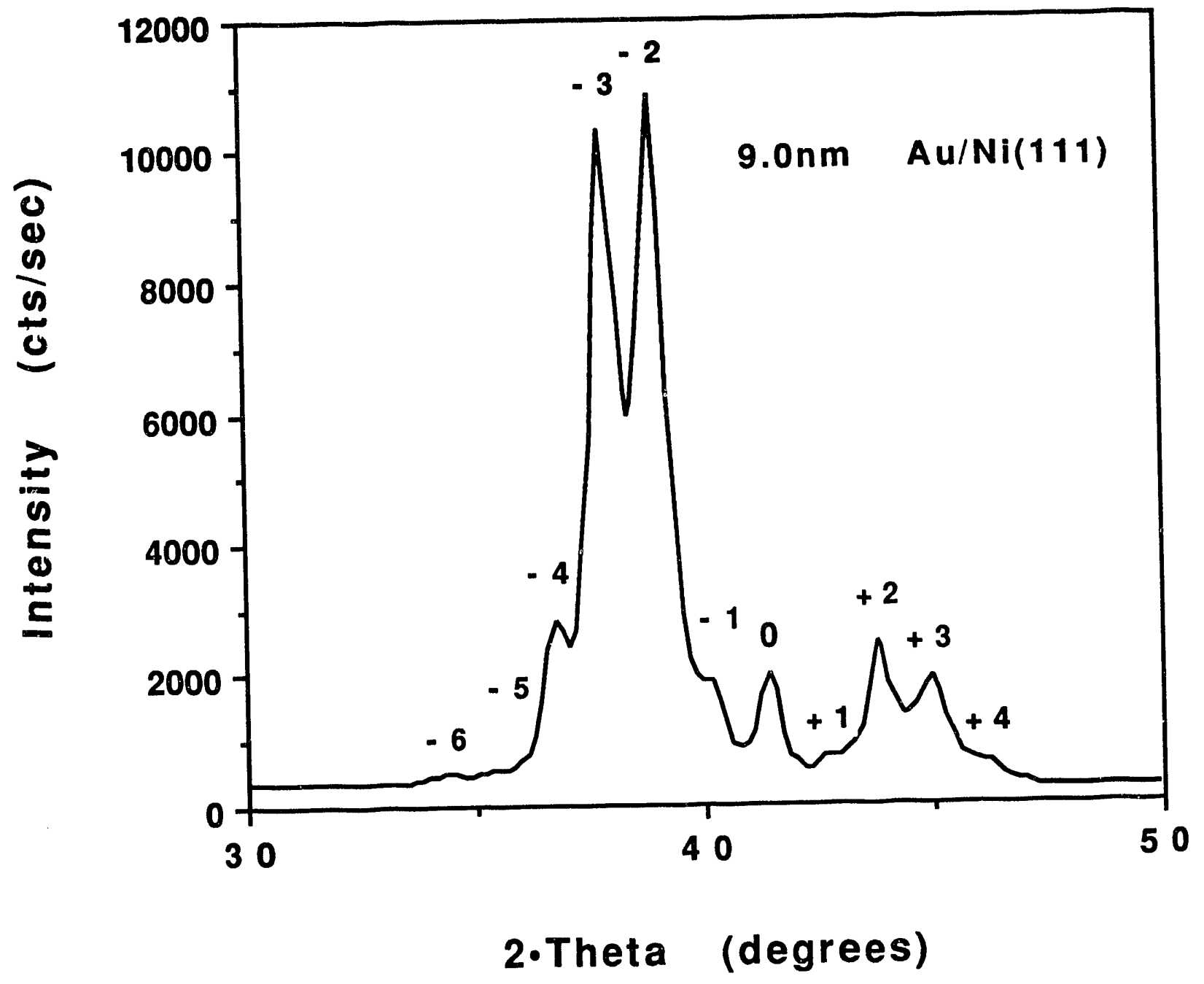

Figure 1. 


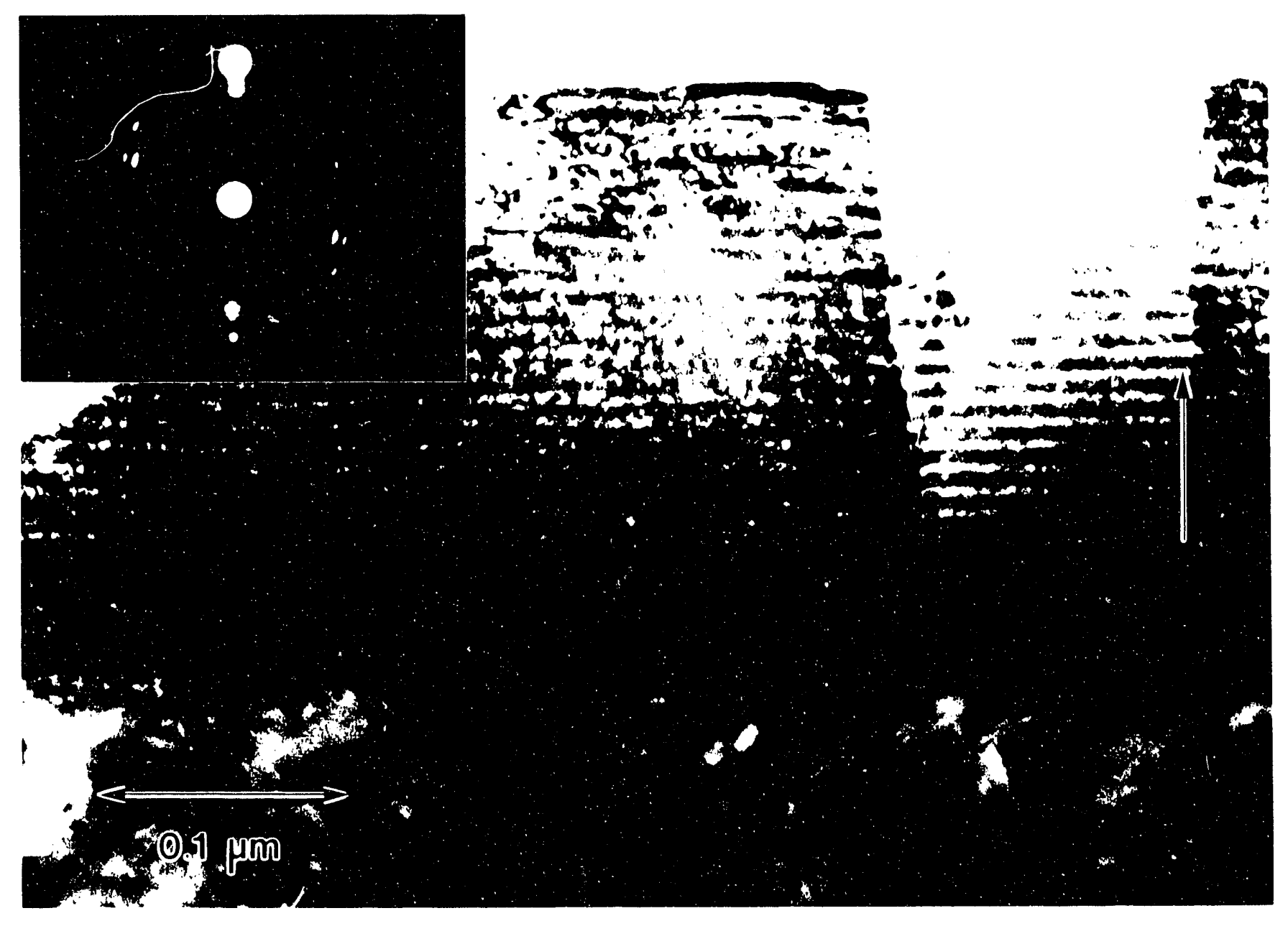

lignare 2. 


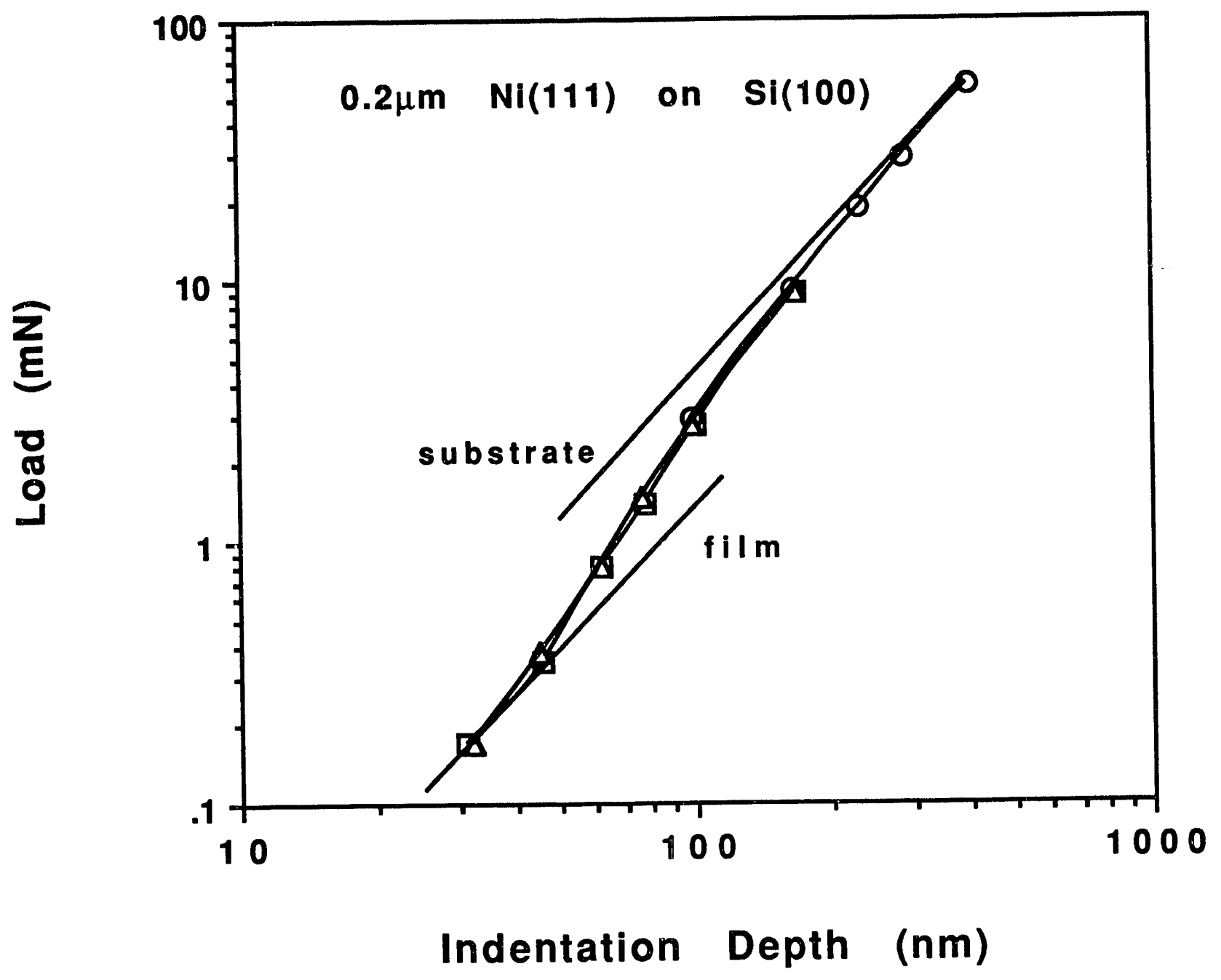

Figure 3. 


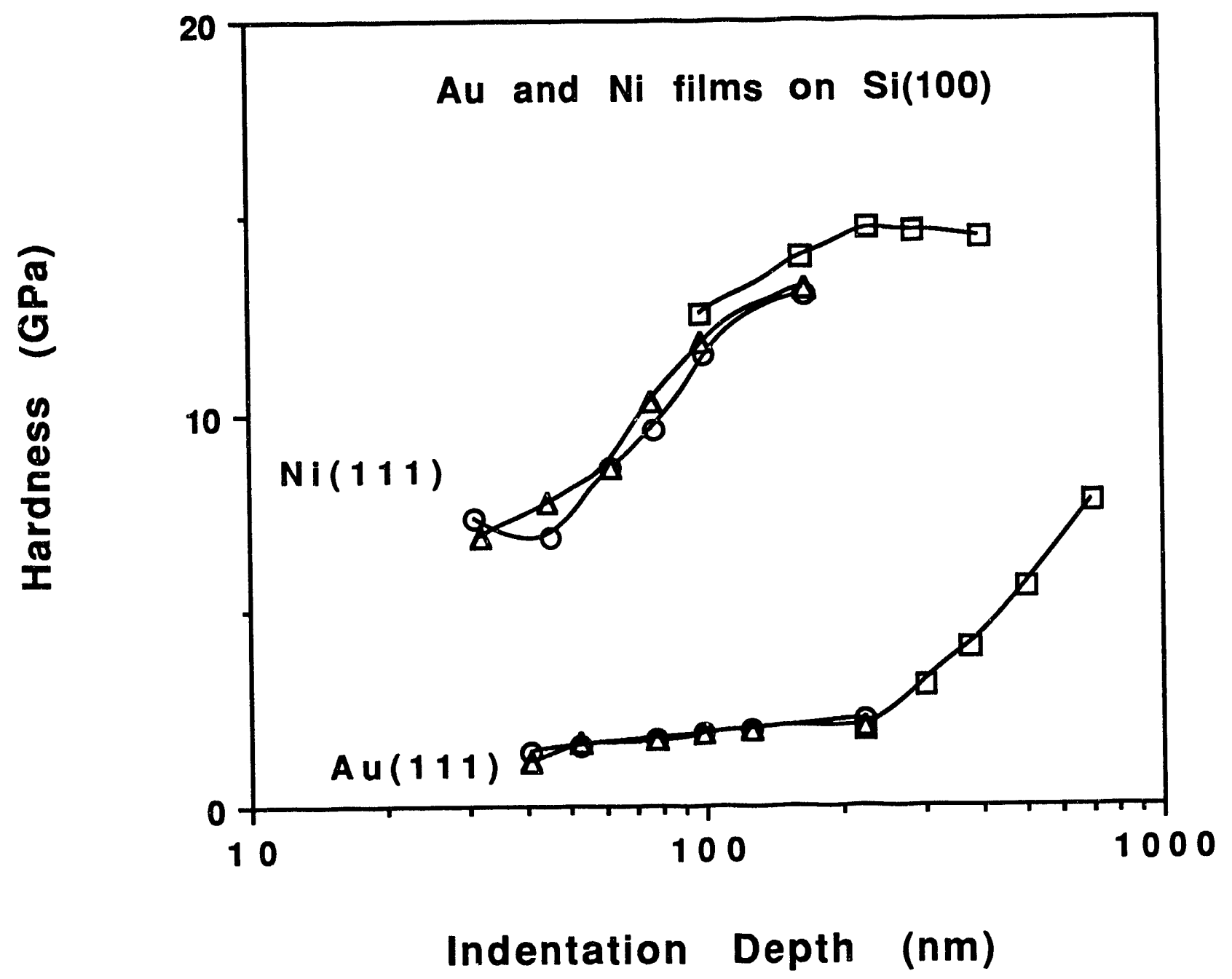

Figure 4. 


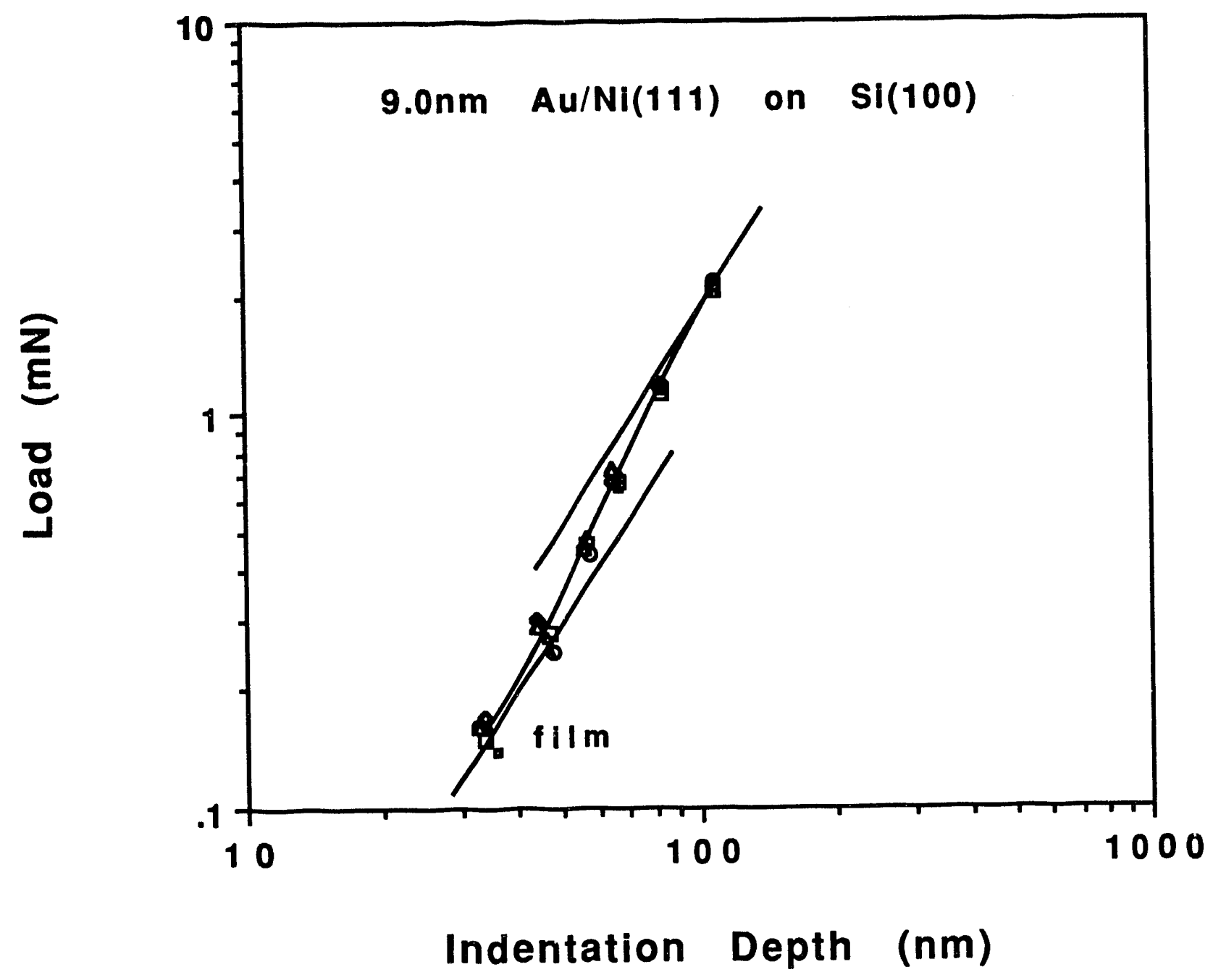

Figure 5. 


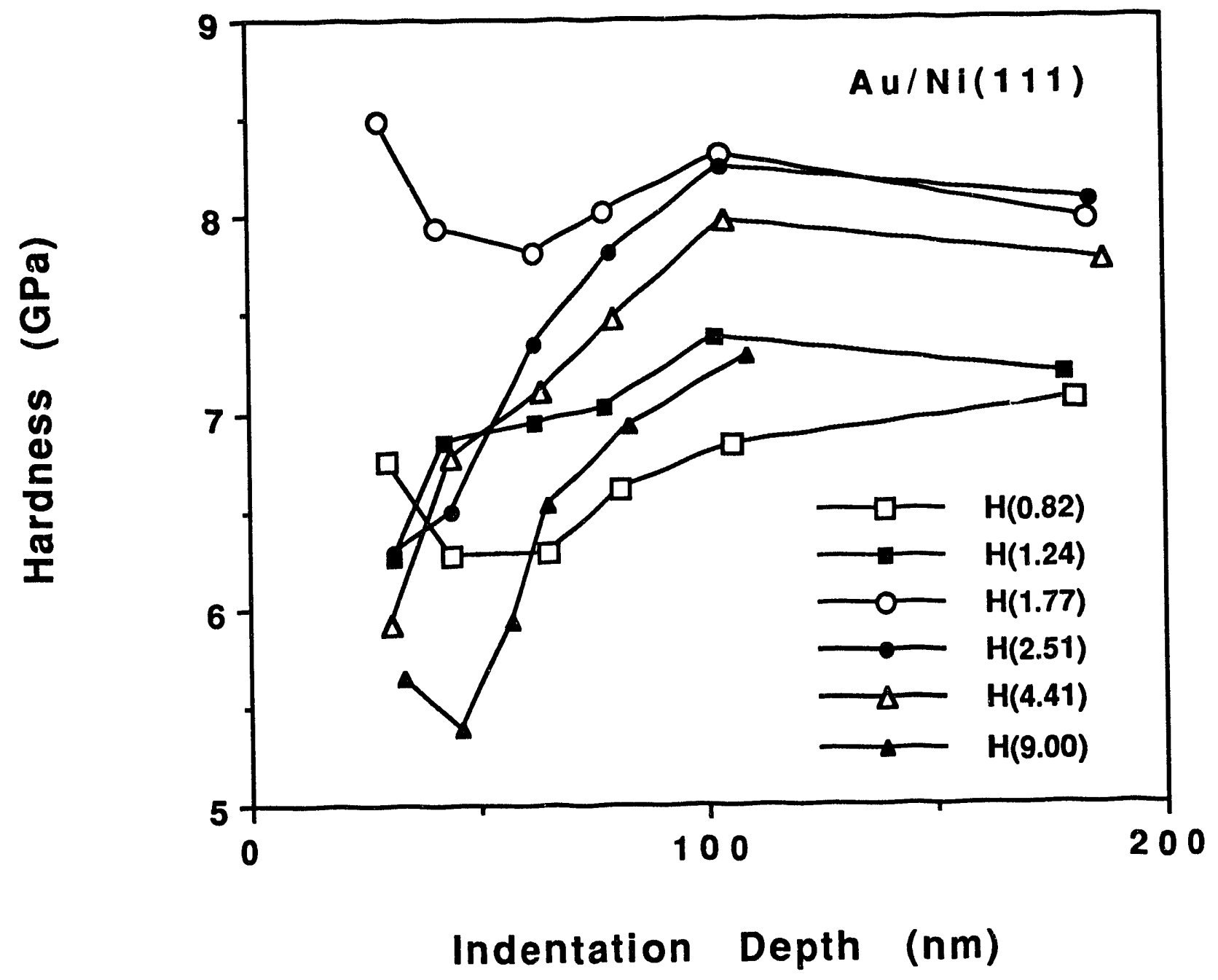

Figure 6. 


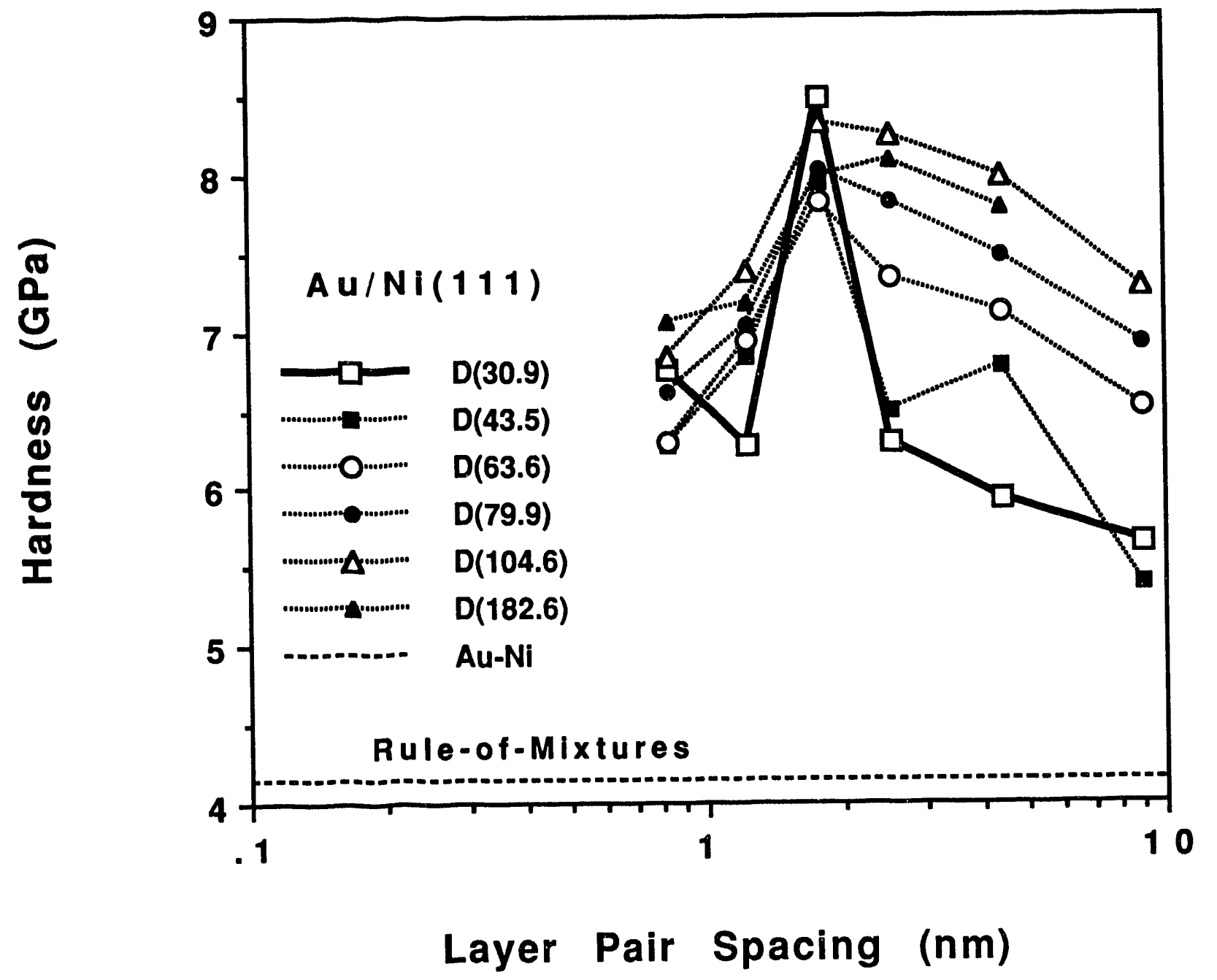

Figure 7. 


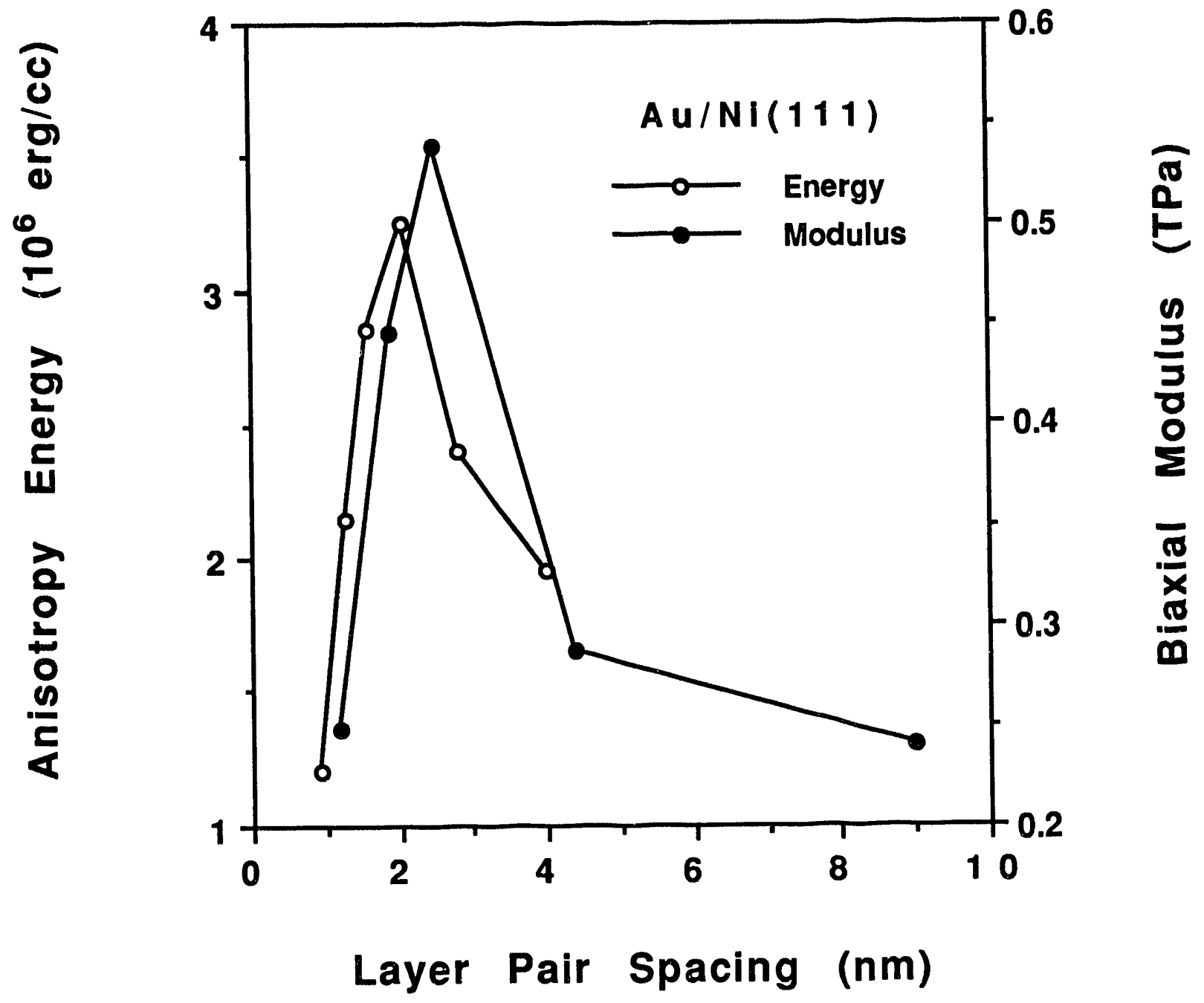

Figure 8. 

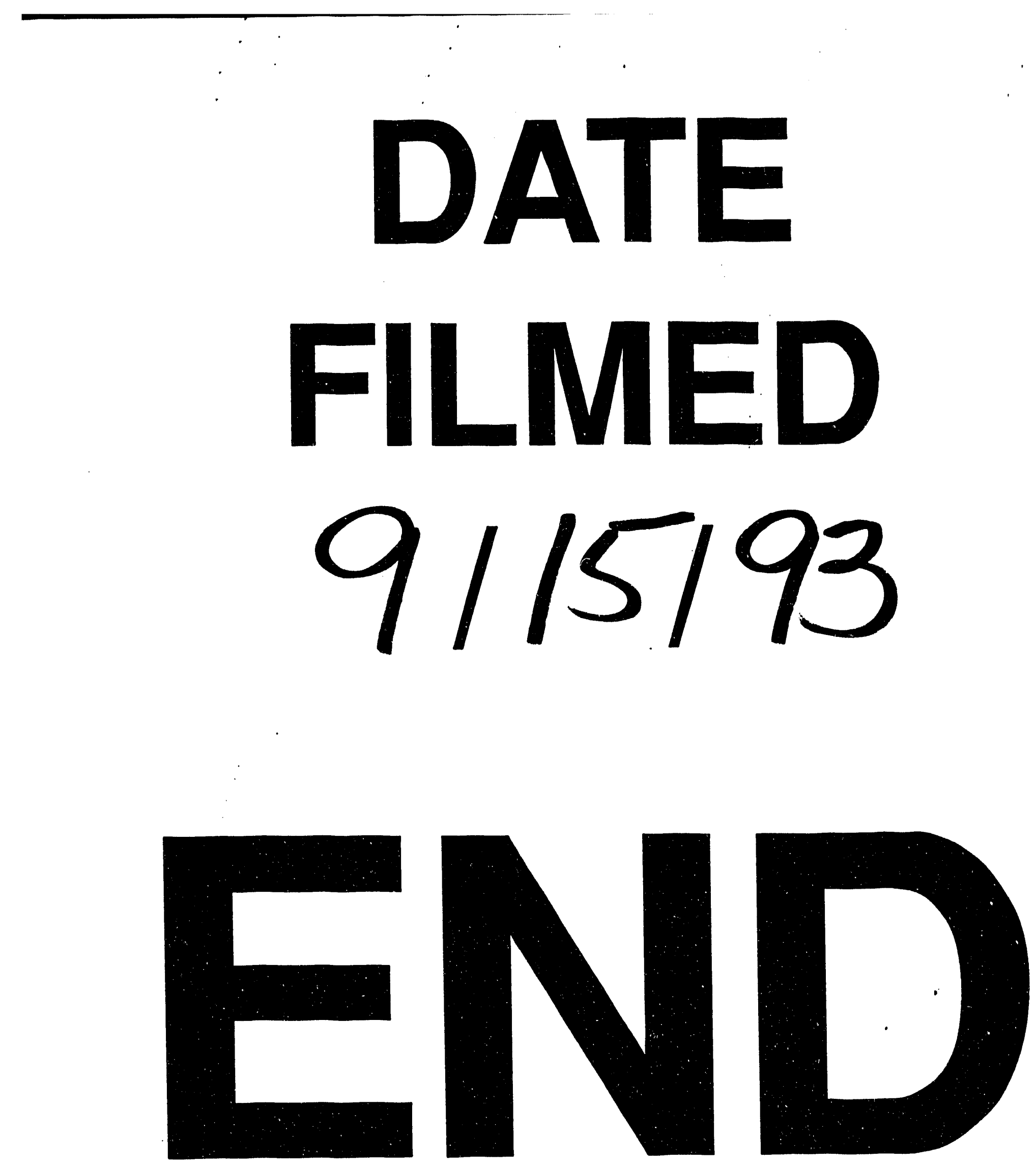